\title{
Changes in clinical practice for central venous access cannulation after the introduction of ultrasound studies in the ICU
}

\author{
Ó Martínez González, D Ballesteros, M Á Alonso Fernández, M Chana, B López Matamala, C Martín Parra, R Blancas \\ From ESICM LIVES 2015 \\ Berlin, Germany. 3-7 October 2015
}

\section{Introduction}

The introduction of ultrasound in the ICU has been extended in recent years. Multiple studies have examined the potential benefits of its use for central venous access canulation, although not yet know what changes occur in clinical practice.

\section{Objectives}

Analyze changes in clinical practice before and after train a group of intensivists in the management of ultrasoundguided technich for central venous access cannulation.

\section{Methods}

Prospective cohort study conducted at the Hospital Universitario del Tajo between September 1, 2011 and September 1, 2014. Two groups were created. A Control Group (CG) involving all central catheters access cannulated between 1 September 2011 and 1 September 2012. The following year the ultrasound was entering in the ICU. The second group, ultrasound group (UG), including all central catheters access cannulated between 1 September 2013 and 1 September 2014. Catheter and localization, the use of ultrasound, date of insertion and removal were collected, major bleeding, pneumothorax, and catheter bacteremia. For statistical analysis, SPSS v20.0 for comparison of qualitative variables the $\chi 2$ test and Student's $t$ test was used for quantitative variables. For rate analysis program Epidat 4.1 was used.

\section{Results}

The number of catheters increased significantly from 141 in CG to 181 in UG. Remarkable was the jugular accesses increased from 35 (24.8\%) to 67 (37.0\%) (Table 1). In the UG 97 (53.6\%) of central veins with ultrasound guidance

Hospital Universitario del Tajo, Critical Care, Aranjuez, Spain
Table 1

\begin{tabular}{llll}
\hline & Control Group & Ultrasound Group & $\mathbf{p}$ \\
\hline Catheters number(\%) & 141 & 181 & 0,004 \\
\hline Basilic & $2(1,4)$ & $1(0,6)$ & \\
\hline Cephalic & $32(22,7)$ & $22(12,2)$ & \\
\hline Femoral & $22(15,6)$ & $36(19,9)$ & \\
\hline Subclavian & $50(35,5)$ & $55(30,4)$ & \\
\hline Yugular & $35(24,8)$ & $67(37,0)$ & 0,026 \\
\hline Ultrasound guided(\%) & $11(7,8)$ & $97(53,6)$ & 0,667 \\
\hline Pneumothorax(\%) & $2(2,4)$ & $3(2,5)$ & 0,084 \\
\hline Bacteremia(\%) & $1(0,7)$ & $7(3,9)$ &
\end{tabular}

were cannulated. The mean length mantenance were 6.43 days in the CG versus 6.35 days in UG $(\mathrm{p}=0.054)$. There wasn't significant differences about pneumothorax observed (Table 1). The bacteremia rates were in the CG of 1.14 / 1000 catheter days and the UG 6.27 / 1000 catheter days, with an RR 5.49 (95\% CI 0.44 to 20.0).

\section{Conclusions}

The use of ultrasound guidance to cannulate central vein access in ICU significantly increases the number of implanted catheters, especially in the jugular. A decrease in pneumothorax or major bleeding is observed. An increase of bacteremia rates is observed.

Published: 1 October 2015

doi:10.1186/2197-425X-3-S1-A73

Cite this article as: Martínez González et al: Changes in clinical practice for central venous access cannulation after the introduction of ultrasound studies in the ICU. Intensive Care Medicine Experimental 2015 3(Suppl 1):A73. 